\title{
Marcada reducción la presión arterial combinando dieta hiposódica y dieta DASH
}

Effects on blood pressure of reduced dietary sodium and the Dietary Approaches to Stop Hypertension (DASH) diet. Sacks F., Svetkey L., Vollmer W.y col. N Engl J Med 2001;344:3-10.

\section{Objetivo}

Evaluar los efectos de tres diferentes niveles de ingesta de sodio y la dieta DASH, sobre la tensión arterial (TA) en individuos hipertensos y sin hipertensión (HTA).

Diseño

Estudio multicéntrico, aleatorizado realizado de 1997 a 1999.

Lugar

Cuatro centros de EE.UU.

Pacientes

Se incluyeron 412 participantes mayores de 22 años, con un promedio de edad de 47 años, que no estuviesen recibiendo medicación antihipertensiva.Sus valores de tensión arterial sistólica (TAS) eran de 120 a $159 \mathrm{~mm} \mathrm{Hg}$, y de diastólica (TAD) de 80 a $95 \mathrm{mmHg}$, (normotensos y con HTA grado 1) basados en el promedio de tres mediciones realizadas en visitas de rastreo previas al estudio. Intervención

Los participantes fueron aleatorizados a consumir una dieta control, típica de EE.UU., o la dieta DASH:elevado contenido en frutas, verduras y lácteos descremados, y reducido de carnes rojas, dulces y bebidas azucaradas. Incluye cereales integrales, carne de ave y pescado, semillas y nueces.Posee cantidades más elevadas de potasio, calcio, magnesio, fibra y proteínas, y menor contenido de grasas y colesterol, en comparación con la dieta control.

Dentro de la dieta asignada los participantes debían consumir tres niveles diferentes de ingesta de sodio, definidos como alto (3,5 gr), intermedio $(2,3 \mathrm{gr})$ y bajo $(1,2 \mathrm{gr})$, durante un período de 30 dias cada uno, en orden aleatorizado.

\section{Medición de resultados principales}

El resultado principal fue la TAS medida al final de cada período de diferente ingesta de sodio, y el resultado secundario la TAD. Los valores de TAS y TAD se compararon entre los tres niveles de ingesta de sodio de cada dieta, y entre las dos dietas, en el mismo nivel de ingesta de sodio.

Resultados principales

La reducción de la ingesta de sodio disminuyó significativamente la TAS y TAD con ambas dietas. La dieta DASH, en comparación con la dieta control, produjo una significativa disminución de la TAS en todos los niveles de ingesta de sodio, y una reducción significativa de la TAD en los niveles alto e intermedio.

La reducción de la ingesta de sodio desde el nivel elevado al inter- medio, disminuyó la TAS $2,1 \mathrm{mmHg}(\mathrm{P}<0.001)$ con la dieta control, y $1,3 \mathrm{mmHg}(\mathrm{P}=0.03)$ con la dieta DASH. La reducción de la ingesta desde el nivel intermedio al bajo de ingesta, produjo una disminución de $4,6 \mathrm{~mm} \mathrm{Hg}$ con la dieta control $(P<0.001)$ y $1,7 \mathrm{mmHg}$ con la dieta DASH $(\mathrm{P}<0.01)$.

El efecto de la disminución de la ingesta de sodio fue mayor en participantes hipertensos que en aquellos sin hipertensión.

La combinación de las dos intervenciones (baja ingesta de sodio y dieta DASH), disminuyó más la TAS en los participantes con hipertensión que en los normotensos ( $P=0.004)$ y más en mujeres que en hombres $(P=0.02)$.

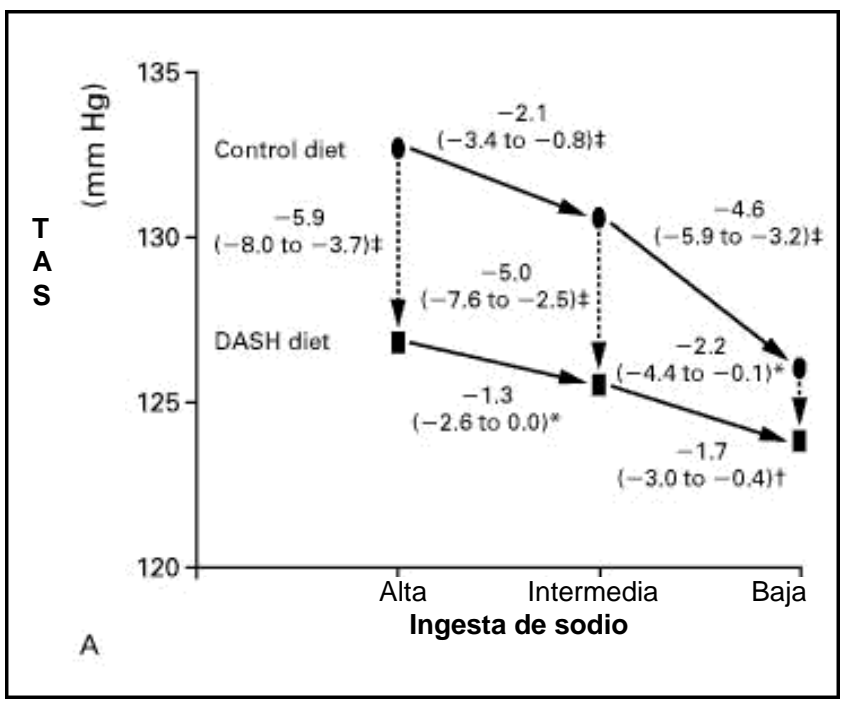

\section{Conclusiones}

La dieta DASH disminuyó la TA en todos los niveles de la ingesta de sodio. En la dieta control se observaron mayores efectos entre el nivel intermedio y bajo de ingesta de sodio.La combinación de la dieta DASH y una baja ingesta de sodio produjo mayores reducciones en los niveles de TA que cada una de las intervenciones consideradas en forma individual.

\section{Comentario}

Este trabajo evaluó la interacción entre dos estrategias para disminuir la presión arterial: la dieta DASH y la disminución de la ingesta de sodio. ${ }^{1}$ Se observó que la dieta DASH disminuyó la TA en tres niveles de ingesta de sodio diferentes, extendiendo los hallazgos del estudio DASH previo ${ }^{2}$ en el cual se mantenía la ingesta de sodio estable en $3 \mathrm{gr} / \mathrm{dí}$. En la dieta control también se observó reducción de la TA en todos los niveles de ingesta de sodio, siendo mayor el efecto entre el nivel intermedio y bajo.Dado que el nivel intermedio corresponde al límite superior de la recomendación de ingesta de sodio en EE.UU., esto sugiere una revisión de las mismas.

Teniendo en cuenta que el mayor aporte sodio de la alimentación proviene de las comidas procesadas y aditivos más que de la sal agregada, es importante orientar a la población en la elección de alimentos bajos en sodio y trabajar con la industria alimentaria. La disminución de la TA se observó tanto en personas con HTA grado 1 , sin HTA, hombres y mujeres, blancos y negros.

El mayor efecto sobre la TA se obtuvo con la combinación de la dieta DASH y la baja ingesta de sodio. Estas reducciones son similares a las que se alcanzan con drogas antihipertensivas.

Los significativos resultados del presente estudio y del DASH previo condujeron a que en las nuevas guías del Comité de Nutrición de la American Heart Association se recomiende tanto a hipertensos como a la población en general un modelo de dieta similar al la dieta DASH, en conjunto con mantener un peso saludable, realizar actividad física, moderar el consumo de alcohol y no fumar.

Conclusión del comentador: La reducción de la ingesta de sodio en combinación con la dieta DASH disminuyó la presión TA a un nivel aún no demostrado por otro tratamiento no farmacológico. La implementación de estas dos intervenciones como una estrategia de salud pública podria ser efectiva en la prevención de la HTA y una alternativa a la medicación para el tratamiento de pacientes con HTA grado 1.

\section{Lic. Liliana Rodota [ Servicio de Alimentación.Hospital Italiano de Buenos Aires]}

\section{Referencias}

1.Svetkey,L, Sacks, F, Obarzanek,E.The DASH diet, sodium intake and blood pressure trial (DASH- SODIUM):rationale and design.J Am Diet.Assoc.1999, 99(suppl): S96-104. 2.Apple, L, Moore, T,Obarzanek,E. A clinical trial of the effects of dietary patterns on blood pressure.(N Engl J Med 1997; 336:1117-24.). 